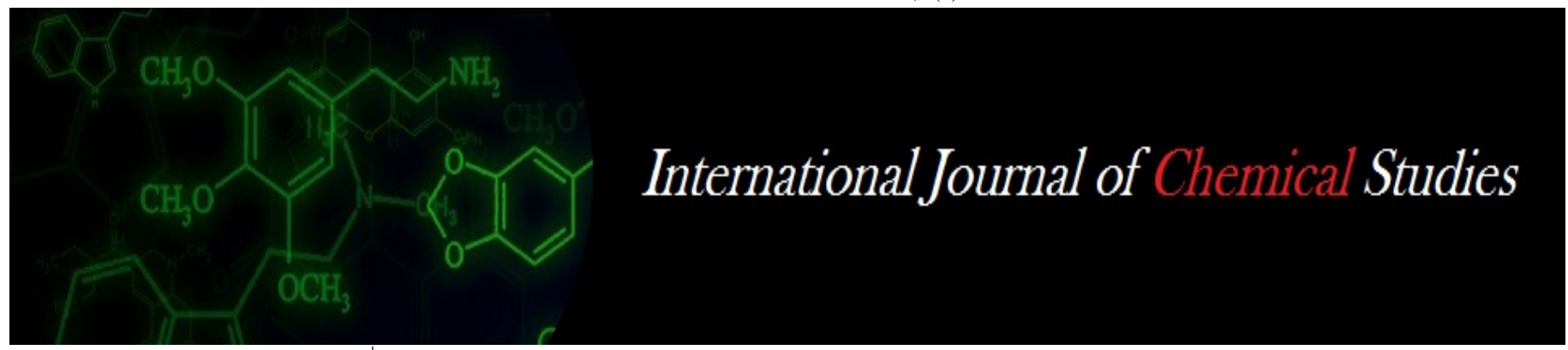

P-ISSN: 2349-8528

E-ISSN: 2321-4902

www.chemijournal.com

IJCS 2020; 8(4): 3514-3517

(C) 2020 IJCS

Received: 20-05-2020

Accepted: 22-06-2020

\section{Shiwanshu Tiwari}

Department of Animal

Husbandry, Sardar Vallabhbhai

Patel University of Agriculture

\& Technology, Meerut,

Uttar Pradesh, India

\section{DS Sahu}

Department of Animal

Husbandry, Sardar Vallabhbhai

Patel University of Agriculture

\& Technology, Meerut,

Uttar Pradesh, India

Manoj Kumar Bansala

Assistant Professor. Department

of Agriculture, Dolphin PG

Institute of Biomedical and

Natural Sciences, Uttarakhand,

India

\section{Balveer Singh}

Scientific Officer (Animal

Science) UPCAR, Uttar Pradesh, India

\section{Nazim Ali}

Department of Animal

Husbandry, Sardar Vallabhbhai

Patel University of Agriculture

\& Technology, Meerut,

Uttar Pradesh, India

\section{Rajbir Singh}

Department of Animal

Husbandry, Sardar Vallabhbhai

Patel University of Agriculture

\& Technology, Meerut,

Uttar Pradesh, India

\section{Rajkumar}

Department of Animal Husbandry, Sardar Vallabhbhai Patel University of Agriculture \& Technology, Meerut,

Uttar Pradesh, India

\section{Corresponding Author:} Manoj Kumar Bansala Assistant Professor, Department of Agriculture, Dolphin PG Institute of Biomedical and Natural Sciences, Uttarakhand, India

\section{Feeding effect of different level of fenugreek powder and vitamin $E$ on carcass quality of broilers}

\author{
Shiwanshu Tiwari, DS Sahu, Manoj Kumar Bansala, Balveer Singh, \\ Nazim Ali, Rajbir Singh and Rajkumar
}

DOI: https://doi.org/10.22271/chemi.2020.v8.i4ar.10196

\begin{abstract}
Present investigation was appraised to study the effect of feeding fenugreek seed powder and vitamin E on feed consumption, live body weight, body weight gain, feed conversion efficiency, dressing percent, giblet weight and intestinal viscera analyzing experimental data collected from 120 birds of Cobb-400 strain carried out at Poultry Research and Training Centre, Sardar Vallabhbhai Patel University of Agriculture \& Technology, Modipuram, Meerut. Birds utilized were selected randomly and divided into four equal groups, each were fed varying diets. For treatments $T_{1}, T_{2}, T_{3}$ and $T_{4}$ dressing percent was computed as $68.02 \pm 0.78,68.56 \pm 57,68.19 \pm 0.51$ and $68.78 \pm 0.55$ while giblets (heart, liver and gizzard) has weighed with quantum of $3.33 \pm 0.11,3.55 \pm 0.03,3.45 \pm 0.12$ and $4.34 \pm 0.13$ percent, respectively. Similarly, intestinal viscera (\%) for all groups were found to be $3.21 \pm 0.08,3.55 \pm 0.18,3.82 \pm 0.03$ and $4.10 \pm 0.05$, respectively. Carcass traits considered for the present study were found to have significant difference among them. According to present trial, combined inclusion of fenugreek seed powder and vitamin $\mathrm{E}$ as $2.0 \mathrm{~g}$ and $50 \mathrm{mg}$ per $\mathrm{kg}$ of feed has adjudged to be better proposition to improve the overall performance.
\end{abstract}

Keywords: Broiler chicks, carcass, fenugreek powder, vitamin E

\section{Introduction}

The world poultry industry has grown consistently since 1940s and the broiler industry has now occupied second place by volume in the world just after pork. Chicken meat represents 29 percent of total meat production from farm animals. Poultry farming in India has transformed itself from backyard venture in to a dynamic agro-industry in few decades and currently possess third and fourth place in egg and broiler production, respectively. Growth promoters are chemical and biological substances added to poultry feed with the aim of improving growth, feed utilization, disease resistance and vitality, regulation of the intestinal micro-flora, reduced morbidity and mortality and in this way realize better production and financial returns. Various types of feed additives such as antibiotics, enzymes, hormones, prebiotics, probiotics, herbal products etc. are used as growth stimulants in poultry production. Fenugreek is an annual legume cultivated across the world, is one of the herbs having multi-functional properties. Husk (seed coat) contains higher amount of polyphenols (103.8 mg of Gallic acid equivalent) and total dietary fiber (77.1\%). Seeds are utilized as appetizer and help in digestion; improve growth performance and health status (Abou El-wafa et al., 2003) ${ }^{[1]}$. Vitamin E is primarily known as an antioxidant in reducing cellular free radical damage but it may also influence the development and maintenance of defense mechanism through multiple functions (Gershwin et al., 1985) ${ }^{[2]}$. Vitamin E consists of two families of compounds, the tocopherols and tocotrienols, characterised by a 6-chromanol ring and an isoprenoid side chain. The members of each family are designated alpha $(\alpha)$, beta $(\beta)$, gamma $(\gamma)$, and delta $(\delta)$ according to the position of methyl groups attached to the chroman nucleus. Therefore, 8 stereoisomers of the large vitamin E family are possible but only the RRR-form occurs naturally. Tocopherols and tocotrienols are differentiated by their phenyl "tails" as these are saturated in the tocopherols but unsaturated in the tocotrienols. 
To get better production and financial returns from a broiler farm, growth promoters are generally added to poultry feed aiming to improve the growth, feed utilization, stimulation of immune system and increased vitality, regulation of intestinal micro-flora, reduced morbidity and mortality by optimizing hepatic functions of the birds. Therefore, present investigation was designed with the intension of getting maximum yield of edible part of broiler's body per unit of feed offered, which in turn can contribute substantially to raise the overall availability of chicken meat per capita.

\section{Materials and Methods}

Data collected on 120 randomly selected unsexed 4-way cross broiler chicks of Cobb-400 strain for growth, feed conversion efficiency and carcass parameters from experimental broiler flock maintained at Poultry Research and Training Centre, SVPUA\&T, Meerut were analyzed for the present investigation. Fenugreek seed powder, Vitamin E and day old broiler chicks were procured from localized market in Meerut district. Four diets with different levels of fenugreek seed powder and vitamin E provided to four groups of birds having three replicates in each group and 10 birds in each replicates. Identical conditions for housing, brooding, feeding and watering on the scientific line were made available to every treatment throughout the entire span of experiment.

Dietary plan of the trial envisaged $\mathrm{T}_{1}$ - Basal ration (control), $\mathrm{T}_{2}$ - Basal ration + Fenugreek seed powder @ 2g/kg of feed, $\mathrm{T}_{3}$ - Basal ration + vitamin E @ $50 \mathrm{mg} / \mathrm{kg}$ of feed and $\mathrm{T}_{4^{-}}$ Basal ration + Fenugreek seed powder $2 \mathrm{~g} / \mathrm{kg}+$ vitamin $\mathrm{E}$ $50 \mathrm{mg} / \mathrm{kg}$ of feed.

\section{Measurement of parameters \\ Carcass parameters}

Three broiler birds were selected randomly from each treatment and weighed for live weight after allowing them fast for overnight. Halal method of slaughter was practiced. Following carcass traits were measure.

Dressed weight $=$ Live weight - blood, feathers, head, shank and skin losses.

$$
\text { Dressing }(\%)=\frac{\text { Dressed weight (deskinned) }}{\text { Live weight }} \text { X } 100
$$$$
\text { Giblet weight }=\frac{\text { Weight of organ in grams }}{\text { Live body weight in grams }} \times 100
$$

$$
\text { Intestine viscera }=\frac{\text { Weight of organ in grams }}{\text { Live body weight in grams }} \times 100
$$

Data were analyzed by using Completely Randomized Design (CRD) under uniform and standard management practices following one way ANOVA procedure of SPSS version 20 (SPSS for windows, V 20.0; SPSS Inc., Chicago, IL, USA). The linear model adopted was:
$\mathrm{Y}_{\mathrm{ijk}}=\mu+\mathrm{T}_{\mathrm{j}}+\mathrm{W}_{\mathrm{k}}(\mathrm{T} \times \mathrm{W})_{\mathrm{ij}}+\mathrm{e}_{\mathrm{ijk}}$

Where, Yijk = Dependent Variable; $\mu=$ Overall Mean; $\mathrm{Tj}=$ Mean effect of Treatments $(\mathrm{j}=1 \ldots 8) ; \mathrm{W}_{\mathrm{k}}=$ Mean effect of Week $(\mathrm{k}=1$...6) and eij = Unexplained residual element assumed to be independent and normally distributed. Testing of significance was done as per Dancan Multi Range Test (DMRT).

Table 1: Composition of fresh fenugreek seeds (Values expressed

\begin{tabular}{|c|c|}
\hline Component & Fenugreek seeds \\
\hline Moisture & - \\
\hline Protein & $30 \mathrm{~g}$ \\
\hline Fat & $7.5 \mathrm{~g}$ \\
\hline Fiber & $50 \mathrm{~g}$ \\
\hline Sapogenins & $2 g$ \\
\hline Trigonelline & $380 \mathrm{mg}$ \\
\hline $\mathrm{Ca}$ & $160 \mathrm{mg}$ \\
\hline $\mathrm{Mg}$ & $160 \mathrm{mg}$ \\
\hline $\mathrm{P}$ & $370 \mathrm{mg}$ \\
\hline $\mathrm{Fe}$ & $14 \mathrm{mg}$ \\
\hline $\mathrm{Na}$ & $19 \mathrm{mg}$ \\
\hline $\mathrm{K}$ & $530 \mathrm{mg}$ \\
\hline $\mathrm{Cu}$ & $33 \mathrm{mg}$ \\
\hline $\mathrm{S}$ & $16 \mathrm{mg}$ \\
\hline $\mathrm{Cl}$ & $165 \mathrm{mg}$ \\
\hline $\mathrm{Mn}$ & $1.5 \mathrm{~g}$ \\
\hline $\mathrm{Zn}$ & $7.0 \mathrm{mg}$ \\
\hline $\mathrm{Cr}$ & $0.1 \mathrm{mg}$ \\
\hline Choline & $50 \mathrm{mg}$ \\
\hline Vitamin C & $43 \mathrm{mg}$ \\
\hline$\beta$-Carotene & $96 \mu g$ \\
\hline Thiamine & $340 \mu g$ \\
\hline Riboflavin & $290 \mu \mathrm{g}$ \\
\hline Nicotinic acid & $1.1 \mathrm{mg}$ \\
\hline Folic acid & $84 \mu g$ \\
\hline
\end{tabular}
per 100g.)

\section{Results and Discussion}

\section{Carcass parameters of experimental birds}

Mean value of dressing percentage for the groups has been presented in Table 2. The mean values of dressing percentage were $68.02 \pm 0.78,68.56 \pm 57,68.19 \pm 0.51$ and $68.78 \pm 0.55$ percentage in group $T_{1}, T_{2}, T_{3}$, and $T_{4}$, respectively. The dressing percentage of the all groups was found to be nonsignificant $(\mathrm{P}<0.05)$. However, dressing percent of broiler chicks differ significantly among the treatment and did not differ in their interaction during study period. Comparable results were shown by Farman Ullah Khan, et al. (2009), Rabia J. Abbas (2010) ${ }^{[16]}$ Omar J. Abo, et al. (2016) ${ }^{[17]}$, K.Y. Yesuf, et al. (2016), Yonatan Kassu et. al. (2016) ${ }^{[19]}$.

Similarly, giblet percentage of broiler chicks significantly differs between the treatments and did not differ in their interaction. Estimated values of giblet weight were observed to be $3.33 \pm 0.11,3.55 \pm 0.03,3.45 \pm 0.12$ and $4.34 \pm 0.13$ percent for group $T_{1}, T_{2}, T_{3}$, and $T_{4}$ respectively. Non-significant difference was observed for giblet weight for all the treatment groups except $\mathrm{T}_{4}$. 
Table 2: Effect of feeding fenugreek seed powder and vitamin $\mathrm{E}$ on dressing percent, giblet weight and intestinal viscera under various treatments

\begin{tabular}{|c|c|c|c|c|c|c|c|}
\hline \multirow{2}{*}{ Parameter } & \multicolumn{4}{|c|}{ Treatments } & \multirow{2}{*}{ Overall Mean } & \multirow{2}{*}{ Pooled SEM } & \multirow{2}{*}{ CD } \\
\hline & $\mathbf{T}_{1}$ & $\mathbf{T}_{2}$ & $\mathbf{T}_{3}$ & $\mathbf{T}_{4}$ & & & \\
\hline Dressing percent & $68.02^{\mathrm{a}}$ & $68.56^{a}$ & $68.19^{a}$ & $68.78^{a}$ & 68.38 & 0.60 & NS \\
\hline Giblet weight (\%) & $3.33^{\mathrm{a}}$ & $3.55^{\mathrm{a}}$ & $3.45^{\mathrm{a}}$ & $4.34^{\mathrm{b}}$ & 3.62 & 0.10 & 0.36 \\
\hline Intestinal viscera (\%) & $3.21^{\mathrm{a}}$ & $3.55^{\mathrm{b}}$ & $3.82^{\mathrm{bc}}$ & $4.10^{\mathrm{c}}$ & 3.67 & 0.09 & 0.35 \\
\hline
\end{tabular}

Averages for intestinal viscera for all four groups have also been presented in Table 2 and were computed as $3.21 \pm 0.08$ $3.55 \pm 0.18,3.82 \pm 0.03$ and $4.10 \pm 0.05$ percent in group $\mathrm{T}_{1}, \mathrm{~T}_{2}$, $\mathrm{T}_{3}$, and $\mathrm{T}_{4}$, respectively. The study revealed that intestinal viscera percentage was higher in $\mathrm{T}_{4}$ with magnitude of $4.10 \pm$ 0.05 which was differ significantly with $T_{1}$ and $T_{2}$, respectively while $T_{3}$ was show the non-significant difference with $\mathrm{T}_{2}$ and $\mathrm{T}_{4}$ group. The average of feed consumption during different weeks from $1^{\text {th }}$ to $6^{\text {th }}$ weeks was found to be almost analogous for all groups. Body weight and feed efficiency was observed significantly higher in treatments groups either fed with fenugreek seed powder (FSP) and vitamin $\mathrm{E}$ combination of both in comparison to control group. Similarly, the feed conversion efficiency was also significantly higher in treatment groups. The usefulness of Trigonella foenum-graecum and Tocopherol as growth promoter and appetizer has improved feed conversion efficiency and increased live body weight which may be attributed to its high content of vitamin $\mathrm{E}$ and antioxidant present in fenugreek seed and vitamin E antimicrobial, immunomodulatory anti-stress, antipyretic, antiasthmatic and analgesic activities present in FSP. The dressing percentage was observed better in Methi and vitamin E supplemented groups. Also the giblet and intestinal viscera percentage percent in treatments groups with Methi and vitamin E supplementation was more when compared with the nonsupplemented groups. Present observation may be compared with the findings of Ihsan T. Tayeb et al. (2012) ${ }^{[20]}$, Jafari et al. (2012) ${ }^{[21]}$, Gamel Ai, et al., (2013) ${ }^{[22]}$, R.M.Patel, et al. (2017) ${ }^{[23]}$ for carcass parameters.

\section{Conclusion}

In general, it was concluded that supplementation of Methi+Vitamin $E$ at an inclusion rate of 2(g.)/Kg+50(mg.)/kg. diet was found optimum and had significant effect on Dressing percent, Giblet weight, Intestinal viscera efficiency. It also improves the carcass parameters of birds, which ultimately yields more economic profits for the poultry farmers.

\section{References}

1. Abou EL-Wafa S, Sayed MAM, Ali SA, Abdallah AG. Performance and immune response of broiler chicks as affected by methionine and zinc or commercial fenugreek supplementations. Egypt Poult Sci. 2003; 23(III):523540.

2. Gershwin M, Beach R, Hurley L. The potent impact of nutritional factors on immune response. In Nutrition and Immunity. Academic Press, New York, 1985, 1-7.

3. Darshana B, Bhaisare D, Thyagarajan R, Richard Churchil, Punniamurthy N. Effect of dietary supplementation of herbal seeds on carcass traits of turkey poults. Veterinary world. 2014; 7:5-7.

4. Tariq Mamoun, Mukhtar Ahmed Mukhtar, Mohamed H Tabidi. Effect of fenugreek seed powder on the performance, carcass Characteristics and some blood serum attributes. Adv. Res. Agri. Vet. Sci. 2014; 1(1):611.

5. Gogary E, Ismail MR, El-Nadi FSA, MI Effect of vitamin $\mathrm{E}$ supplementation and stocking density on broiler performance, carcass traits and histological responses of lymphoid organs, Asian Journal of Poultry Science. 2015; 9(2):70-84.

6. Shashi Kant, Nazim Ali, Gulab Chandra, Rakesh Kumar Singh. Effect of shatavari and vitamin $\mathrm{E}$ on growth performance, biochemical profile and dressing percentage of broilers during winter season. Indian Journal of Poultry Science. 2015; 50(2):158-162.

7. Nadir Alloui S, Ben Aksa MN, Alloui, IBRIR F. (Animal Production Division, INSVSA, University of Batna, Algeria .Utilization of Fenugreek (Trigonella foenumgraecum) as Growth Promoter for Broiler Chickens. J. World's Poult. Res. 2012; 2(2):25-27.

8. Weerasingha AS, Atapattu NSBM. Effects of fenugreek (trigonella foenum-graecum L.) Seed powder on growth performance, visceral organ weight, serum cholesterol levels and the nitrogen retention of broiler chicken. Tropical Agricultural Research. 2013; 24(3):289-295.

9. Rahman HA, Abdel et al., 2014

10. Patel RM, Garg DD, Patel VR, Vahora SG, Katariya MA, Choubey M. Effect of Dietary Supplementation of Garlic (Allium sativum) and Fenugreek (Trigonella foenumgraecum L.) Seed Powder on Growth Performance, Carcass Characteristics and Economics of Feeding in Broilers, Journal of Animal Research. 2014; 7(2):313318.

11. Singh VS, Jyoti Palod, Stuti Vatsya, Shukla SK. Effect of herbal vitamin E selenium with organic chromium on growth, haematological and parasitological parameters of broiler chicken during mixed Eimeria infection. Veterinary Research International. 2013; 1:25-30.

12. Safarizadeh A, Zakeri A. The effect of vitamin A and complex of vitamin $\mathrm{E}$ and selenium on growth factors and Humoral immunity in broiler chickens European Journal of Experimental Biology. 2013; 3(4):99-102.

13. Safaei A, Rahanjam SM, Gharajanlu M. Effect of foenum-graecum on immune response and some blood parameters of broilers. Scholarly Journal of Agricultural Science. 2013; 3(4):117-120.

14. Rodica DC, Tatiana P, Anca B, Iulia Varzaru, Mariana R, Gabriela MC. Study on the use of fenugreek in laying hens diet on egg quality. National Research and Development Institute for Biology and Animal Nutrition, 2013, 1-5.

15. Farman Ullah Khan, Assad Ullah, Sajid-ur-Rehman, Shabana Naz, Naureen Rana. Fenugreek (Trigonella foenum-graecum L.) effect on muscle growth of broiler Chicks, ROAVS. 2011; 1(1):1-3

16. Rabia Abbas J. Effect of Using Fenugreek, Parsley and Sweet Basil Seeds as Feed Additives on the Performance of Broiler Chickens, International Journal of Poultry Science. 2010; 9(3):278-282. 
17. Omar Abo J, Hejazi A, Badran R. Performance of Broilers Supplemented with Natural Herb Extract. Open Journal of Animal Sciences. 2016; 6:68-74.

18. Yesuf KY, Mersso BT, Bekele TE Effects of different levels of turmeric, fenugreek and black cumin on carcass characteristics of broiler chicken, J Livestock Sci. 2017; 8:11-17.

19. Yonatan Kassu, Berhan Tamir, Etalem Tesfaye. Effect of Supplementing Natural Feed Additives: Black Cumin, Fenugreek and Turmeric on the Growth Performance and Economic Efficiency of Broiler Chickens. Advances in Biological Research. 2016; 10(5):335-344.

20. Ihsan T Tayeb, Gelawesh Khelil Qader. Effect of Feed Supplementation of Selenium and Vitamin E on Production Performance and Some Hematological Parameters in Broiler, KSU J Nat. Sci. 2012; 15(3):4656.

21. Jafari RA, Kiani R, Shahriyari A, Asadi F, Hamidinejat H. Effect of dietary vitamin E on plasma oxidative stress in broiler chicks infected with Eimeriatenella, Comparative Clinical Pathology. 2012; 21(5):895-899.

22. Gamel Al, Abdelrahman MA, Gihan AS, Arafa HE, MM, El-Shafei AA. Study the impact of EDTA and vitamin E supplementation in diet on physiological, biochemical and histo-pathological pictures of broiler chicks, The Journal of American Science. 2013; 9(4):543-562.

23. Patel RM, Garg DD, Patel VR, Vahora SG, Raval AP, Choubey M. Effect of Dietary Supplementation of Garlic (Allium sativum) and Fenugreek (Trigonella foenum graecum L.) Seed powder on growth performance, carcass characteristics and economics of feeding in broilers, Journal of Animal Research. 2017; 7(2):313318. 